
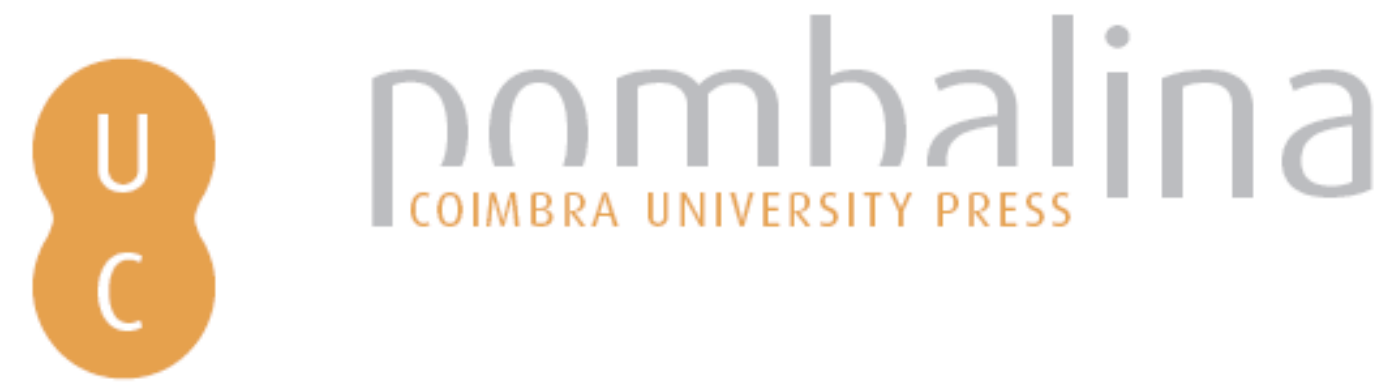

\title{
A exportação de produtos lusitanos na Antiguidade Tardia: rotas, cargas e naufrágios no Mediterrâneo Ocidental (Séculos III a VI)
}

\author{
Autor(es): Bombico, Sónia
}

Publicado por: Imprensa da Universidade de Coimbra

URL

persistente: URI:http://hdl.handle.net/10316.2/42114

DOI: $\quad$ DOI:https://doi.org/10.14195/978-989-26-1353-6_8

Accessed : $\quad$ 26-Apr-2023 14:52:13

A navegação consulta e descarregamento dos títulos inseridos nas Bibliotecas Digitais UC Digitalis, UC Pombalina e UC Impactum, pressupõem a aceitação plena e sem reservas dos Termos e Condições de Uso destas Bibliotecas Digitais, disponíveis em https://digitalis.uc.pt/pt-pt/termos.

Conforme exposto nos referidos Termos e Condições de Uso, o descarregamento de títulos de acesso restrito requer uma licença válida de autorização devendo o utilizador aceder ao(s) documento(s) a partir de um endereço de IP da instituição detentora da supramencionada licença.

Ao utilizador é apenas permitido o descarregamento para uso pessoal, pelo que o emprego do(s) título(s) descarregado(s) para outro fim, designadamente comercial, carece de autorização do respetivo autor ou editor da obra.

Na medida em que todas as obras da UC Digitalis se encontram protegidas pelo Código do Direito de Autor e Direitos Conexos e demais legislação aplicável, toda a cópia, parcial ou total, deste documento, nos casos em que é legalmente admitida, deverá conter ou fazer-se acompanhar por este aviso.

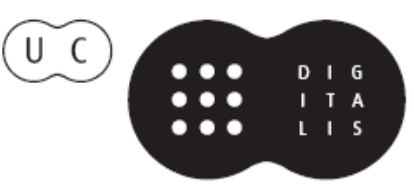




\section{Arqueologia \\ da transição:}

entre o mundo romano

e a Idade Média

Cláudia Teixeira, André Carneiro (coords.)

IMPRENSA DA UNIVERSIDADE DE COIMBRA

ANNABLUME 


\title{
A exportação de produtos lusitanos na Antiguidade Tardia: rotas, Cargas e naufrágios no Mediterrâneo Ocidental (Séculos III a VI) - Dados Preliminares (Exportation of lusitanian products: preliminary data for routes, cargoes and shipwrecks in Late Antiquity Western Mediterranean (III-VIth centuries))
}

\author{
Sónia Bombico (sbombico@uevora.pt) \\ CIDEHUS - Universidade de Évora
}

\begin{abstract}
Resumo - A presença de cerâmicas de importação datáveis da Antiguidade Tardia, na antiga província romana da Lusitânia, surge em perfeita relação com a longevidade dos centros produtores de preparados piscícolas e a produção de contentores anfóricos, cujas últimas investigações têm atestado para além dos inícios do século $\mathrm{V}$ com provável continuidade até ao século VI. A difusão de ânforas de produção lusitana no Mediterrâneo, em contextos subaquáticos e terrestres litorais, têm possibilitado o estudo das principais rotas utilizadas para a exportação dos preparados de peixe lusitanos.
\end{abstract}

Palavras-chave - Antiguidade Tardia; rotas marítimas; naufrágios; ânforas lusitanas.

Abstract - The presence of imported ceramics from the Late Antiquity, in the Roman province of Lusitania, appeared in perfect relationship with the longevity of amphorae and salted fish productions, whose latest investigations have confirmed beyond the early fifth century and probably until the sixth century. The diffusion of Lusitanian amphorae in the Mediterranean, in underwater and terrestrial coastal environments, has allowed the study of the main routes used for the export salted fish from Lusitania.

KEYwords - Late Antiquity, maritime routes, shipwrecks, Lusitanian amphorae.

\section{O Ocidente Peninsular e as redes de intercâmbio com o Mediterrâneo: Continuidades e Rupturas}

A presença de cerâmicas de importação, datáveis do final do domínio romano, nos contextos arqueológicos lusitanos tem contribuído para a perceção de uma continuidade das estruturas económicas de trocas, que em muitos contextos se prolonga para além da queda do Império Romano do Ocidente. Ânforas africanas e orientais, sigillatae tardias claras (africanas), cipriotas, foceences e hispânicas tardias, difundidas entre os meados do século $\mathrm{V}$ e o século VI, revelam uma plena integração do Ocidente da Península Ibérica, já sob o domínio dos povos bárbaros, na vasta rede de comunicações e intercâmbios com o Império Romano do Oriente (Fabião 2009a).É provável que as contrapartidas do Ocidente Peninsular passassem pela continuidade da exportação de preparados piscícolas (garum, liquamen, allec, muria e produtos similares). 
Entre os finais do século in e os inícios do século in registam-se profundas alterações na produção de preparados de peixe na Lusitânia, mudanças que se verificam ao nível da organização das unidades e dos centros oleiros, e que se fazem sentir nos registos de importação da generalidade dos sítios do Mediterrâneo Ocidental (Fabião 2008: 735 e Fabião 2009b). Este período de transição é marcado pelo abandono de algumas unidades de produção e pela reestruturação ou subdivisão dos tanques de salga. A descontinuidade na produção lusitana ajusta-se perfeitamente ao ocorrido no âmbito do "Círculo do Estreito" (Villaverde Vega 1990; Lagosténa Barrios 2001; Bernal Casasola 2008).

Estas transformações são geralmente associadas às medidas Severianas. A política dos Severos prejudicou os lucros da indústria de azeite da Bética, com a expropriação de propriedades e a passagem do controle da produção e distribuição para o Estado. As elites financeiras regionais, nas quais se poderiam incluir também os grandes proprietários das unidades de produção de preparados de peixe, foram objetivamente prejudicados (Reynolds, 2010: 26 e 41).

Desta forma, o século iıI marcou o início de um conjunto de alterações no quadro das dependências interprovinciais. Assistiu-se a uma nova estrutura do comércio marítimo, na qual as rotas africanas ganham especial importância, na sequência do florescer das produções oleárias e piscícolas das províncias do Norte de África, sobretudo da África Proconsular, Bizacena e Tripolitana (Mantas 1998: 238). A annona parece ter estimulado o transporte de produtos da África, como antes havia feito com os béticos (Wickham 1988 apud Padilla Monge 2008). A partir de meados do século IV, a África converte-se no abastecedor de azeite maioritário em Roma (Padilla Monge 2008: 362).

$\mathrm{Na}$ Lusitânia, a exploração e a exportação de preparados de peixe atinge um evidente florescimento ao logo do século IV, mantendo-se em pleno funcionamento até ao século v (Fabião 2009b: 571).

A falta de dados precisos, quanto ao número e às dimensões dos tanques de salga, tem dificultado os estudos relativos à quantificação da produção. Ainda assim têm-se projetado alguns estudos preliminares, como o levado a cabo por Andrew Wilson (2006). De alguma forma contrariando a evolução global no mundo romano, as regiões ocidentais da Lusitânia e as costas Norte Africanas e Hispânicas, em torno do Estreito de Gibraltar, registam uma produção estável e com níveis bastante elevados, entre o século III e o início do v. Níveis associados a dois momentos de investimento no aumento da capacidade de produção e reestruturação das unidades de produção, ocorridos nas primeiras metades dos séculos III e IV (Wilson 2006).

A investigação das últimas décadas tem permitido atestar a laboração de algumas unidades para além dos inícios do século $\mathrm{v}$, e nos contextos de Lagos (Rua 25 de Abril e Rua Silva Lopes) até ao século vi (Fabião 2009a e Bernal Casasola 2008). 
Durante os séculos IV e v, as olarias do Sado e do Tejo apresentam um grande dinamismo, o que sugere um pico de consumo e exportação dos produtos lusitanos (Fabião 2008: 740). Os dados atuais têm permitido atestar a continuidade da produção no contexto sadino até aos finais do século $\mathrm{v}$ e inícios do VI, e os contextos estratigráficos da cidade de Lisboa tem revelado abundantes materiais anfóricos de produção local em níveis do século Vi e inícios do VII (Fabião 2008: 743). Os centros oleiros da região algarvia ganham especial importância nesta época, afirmando-se como a área produtora mais relevante, com produções atestadas para Martinhal até aos inícios do século v, e em Lagos (Rua 25 de Abril e Rua Silva Lopes) com provável prolongamento da produção até ao Vi (Fabião 2008: 740 e Fabião 2009a). Podemos, assim, assumir que a produção e a exportação de produtos lusitanos se mantiveram, ainda que em menor escala, durante todo o século $\mathrm{v}$ e os inícios do século vi, ou seja, até momentos claramente posteriores à queda do Império Romano do Ocidente.

Em meados do século iv e durante o século v, assistimos a um aumento do número de naufrágios de origem hispânica no Mediterrâneo, cuja frequência parece aumentar após um período de alguma ausência (GarcíaVargas 2011: 101). Por outro lado, a distribuição geográfica dos naufrágios, segundo os dados de Parker, evolui de um predomínio da área ocidental no século IV, para uma maior número de registos na área oriental associada ao domínio Bizantino, nos séculos vi e viI (Volpe 2002: 242).

Durante a Antiguidade Tardia os produtos ibéricos, particularmente as conservas de peixe da Bética e da Lusitânia envasados nas ânforas de tipo Keay XIX e Keay XXIII, estão presentes no Oriente, havendo sido documentadas em Beirut, Palmira, Beit She'an (Israel), Kibbutz Reshafim (Beit She'an), Samira e Caesarea Maritima (Bernal Casasola 2000; Padilla Monge 2008; García Vargas 2011: 101 e Reynolds 2010).

Sob o domínio Vândalo, o Norte de África continuou a fazer chegar os seus produtos às costas do sul da Europa. Os numerosos registos de cerâmica africana e oriental, dos séculos v e vi, nas costas narbonenses, tirrénicas e ligúricas podem ser associados à rota Roma-Arles retratada no Itinerarium maritimum (apêndice do Itinerarium Antonini). Obra cuja datação tem vindo a ser atribuída à segunda metade do século v (Uggeri 2002: 712-713).

A partir de 533/534 o Estreito de Gibraltar é objecto de ocupação pelas tropas de Justiniano, que se inicia com a tomada de Septem (actual Ceuta) e se amplia até Carthago Spartaria (Cartagena). Domínio que se vai prolongar no tempo até finais do seculo viI (Bernal Casasola 2004: 55).

O progressivo abandono das unidades produtoras de preparados de peixe, a partir de meados do século vi, tem sido associada à conquista Bizantina da área integrada no "Círculo do Estreito". Assiste-se ao fim do sistema tradicional de produção, ao consecutivo abandono das unidades e ao desapareci- 
mento das ânforas de preparados piscícolas do sul da Hispânia (Almagro 50 e $51 \mathrm{c}$ e a-b) dos mercados mediterrâneos. Sobrevivem as formas designadas de spatheia de produção sul-hispânica e levantina, que se vão tornando cada vez mais comuns durante o século v, vi e vir (Bernal Casasola, 2004; 2008). $\mathrm{Na}$ opinião de Bernal Casasola (2004) devemos entender esta questão como um problema de geoestratégia comercial. A decadência da produção ibérica parece estar associada a medidas protecionistas que visavam o favorecimento das produções pesqueiras e vinárias da fachada africana do Império Bizantino. O enfraquecimento das produções lusitanas e béticas terá ocorrido a par do franco desenvolvimento das suas congéneres norte africanas, que conjuntamente com a produção de azeite começaram a dominar nos mercados do Mediterrâneo Ocidental.

Efectivamente, durante os séculos vi e vil ganham especial destaque, no Ocidente, as cerâmicas africanas e orientais. Para tal deve ter contribuído o sistema anonário. A necessidade de abastecer as tropas destacadas no Ocidente parece ter feito desenvolver um eficiente sistema de abastecimento, perceptível também na Itália Bizantina (Bernal Casasola 2004: 57).

No entanto, a elevada percentagem de ânforas orientais no "Círculo do Estreito" parece atestar, também, a intensa atividade dos transmarini negotiatores citados pelas fontes. Cuja atividade não parece ter sido interrompida nem com a presença dos Vândalos, nem pela conquista Bizantina (Expósito Álvarez e Bernal Casasola 2007: 125).

Nos últimos anos, a arqueologia tem registado a multiplicação de sítios arqueológicos com importação de ânforas orientais. Chegaram ao Ocidente Peninsular, entre os séculos IV e viI, as ânforas dos tipos LRA 1, 2, 3 e 4 de produção da Asia Menor, do Egeu, Síria, Palestina e Egipto (Garcia Vargas 2011: 78). A sua presença em território português tem vindo a ser atestada em Bracara Augusta, Olisipo, Conimbriga, entre outros locais ao longo da fachada atlântica (Fabião 2009: 37, fig.5 e Morais 1998). As produções cerâmicas africanas e os tipos anfóricos orientais (LRA 1,2,3 e 4) estão também documentados em Vigo e nas Rias Baixas, a partir do século iv e v (Fernández Fernández 2010: 234-235).

Estas importações precedentes da Pars Orientalis do Império são evidências de um comércio ativo Oriente-Ocidente, no qual as colonias de comerciantes orientais residentes na Península Ibérica (os syrrii e graeci das fontes) detinham um papel estratégico fundamental enquanto agentes comerciais (Expósito Álvarez e Bernal Casasola 2007: 125; Pieri 2002).

A intervenção da Igreja na produção e comercialização de produtos tem sido questionada (Bernal Casasola 2008; 2010). Por um lado pode-se atribuir uma função decorativa aos motivos religiosos reproduzidos nas lucernas e na sigillata clara de produção africana; decorações associadas à ampla difusão de cenas religiosas em todo o tipo de suportes desde a oficialização do Cristianismo, nos 
finais do seculo iv. Por outro lado, os dados arqueológicos permitem demonstrar a participação de agentes eclesiásticos tanto na produção como no comércio de alimentos a grande distância (Bernal Casasola 2010; 20).

O primeiro indício arqueológico reside na existência de grafitos com motivos religiosos nas séries anfóricas norte africanas entre meados do século IV e os séculos vi/vir. A localização dos grafitos de tipo simbólico in collo, como o crismón e a cruz, parecem surgir na sequência da tradição dos selos, fazendo referencia provavelmente ao produtor (Bernal Casasola 2010; 21). O exemplo mais ilustrativo desta prática são as ânforas africanas de tipo Keay LXII, LV entre outras, do naufrágio de La Palud, no sul da França, datado da primeira metade do século vi (Long e Volpe 1996 apud Bernal Casasola 2008: 41). No entanto, esta interpretação não anula a existência, em paralelo, da prática de anotações comerciais pintadas efectuadas pelos transmarini negotiatores, normalmente em grego e a tinta vermelha. Na qual a utilização de símbolos religiosos tem sido associada ao carácter sagrado das mercadorias transportadas (vinhos e azeites), destinados a usos litúrgicos (Bernal Casasola 2008: 41).

Atualmente, ainda que de maneira tímida, os arqueólogos começam a utilizar epítetos, como ânforas procedentes de "olarias eclesiásticas", que até há poucos anos eram impensáveis (Bernal Casasola 2010: 24).

A segunda evidência reside na íntima conexão entre a localização de basílicas e mosteiros e os centros de produção alimentar. Nesse sentido Bernal Casasola enumera alguns exemplos de conexões físicas entre diversas fábricas de preparados de peixe tardo-romanas e alguns centros basilicários ou episcopais, tais como a basílica de Septem, actual Ceuta, e a fábrica de preparados de peixe da Rua Queipo de Llano, em laboração no século V; as instalações industriais de Valentia, no interior de um edifício administrativo, próximas da área sagrada de "Cárcel de San Vicente"; ou as cetariae de Barcino activas entre os séculos iıI e v, no entorno do núcleo episcopal (Bernal Casasola 2010: 23).

Apesar da complexidade do tema e das controvérsias a ele associadas, estas evidências são extrapoláveis ao caso de Tróia, na Península de Setúbal. A edificação da Basílica paleocristã de Tróia, instalada no final do século Iv (Vaz Pinto, Magalhães e Brum 2011), é contemporânea à plena laboração de algumas oficinas do complexo industrial.

Ainda segundo Darío Bernal Casasola, a importância dos episcopados tardo-antigos poderá estar por detrás da pujança económica detectada em algumas regiões a partir do século Iv. Um bom exemplo desse desenvolvimento poderá ser o floruit da produção cerâmica, na qual se inclui a produção de ânforas, na área ocidental da Andalusia, no entorno de Onuba (Bernal Casasola 2010: 23). Ao qual poderemos juntar o reflorescer da produção Lusitana, e em particular a área de produção Algarvia. 


\section{ÂNFORAS DE TRANSPORTE DE PRODUÇão LUSITANA (SÉCULOS III A VI) ${ }^{1}$}

Durante a fase tardia de produção de ânforas proliferam, nas olarias da Lusitânia, um conjunto de novas formas que vêm substituir a Dressel 14, o tipo clássico de ampla produção do Alto Império. Nos centros do Tejo e Sado destacam-se as formas Almagro 51c, Almagro 50 e Keay XVI (formas 4, 5 e 6 da tipologia de Dias Diogo). A Almagro 51c é normalmente considerada herdeira da forma Lusitana 3. Surgem ainda as formas Keay 78 do Sado (equivalente à forma 91 de Guilherme Cardoso, à Lusitana 8 de Dias Diogo ou Sado 1 de Mayet e Silva) e a Lusitana 9 de fundo plano (tipologia de Dias Diogo e equivalente à Sado 2 de Mayet e Silva), produzida também no estuário do Tejo. No decorrer dos séculos Iv e $\mathrm{v}$ surge a forma Almagro $51 \mathrm{a}-\mathrm{b}$, muito embora seja igualmente associada aos finais do século III (Fabião 2004; 2008; Mayet 2001).

Em momentos tardios, já dos finais do século iv e inícios do v, surgem novas morfologias como a designada Sado 3, identificada em níveis tardios de Santarém e Cartago (Fabião 1996: 381; Fabião 2008: 742; Fabião 2009b: 575), e no naufrágio de Cala Reale $\mathrm{A}$, onde surgem associadas às de tipo Almagro $51 \mathrm{a}-\mathrm{b}$ (Spanu 1997 e Gasperetti 2012).

A forma Beltrán 72, durante muito tempo considerada como uma produção algarvia, parece ter sido definitivamente excluída das produções lusitanas pela maioria dos autores e enquadrável nas produções tardias da área da baía gaditana (Fabião 2004: 397). Ainda assim, alguns estudos de materiais cerâmicos recentes continuam a fazer referência a formas deste tipo com pastas lusitanas, o que mantém a questão em aberto (Garcia Vargas 2007: 343).

Para além do panorama sumariamente apresentado, existe ainda um conjunto de tipos minoritários, ainda mal caraterizados e que poderão ter tido uma difusão apenas regional. A produção lusitana de ânforas encontra-se intimamente ligada ao transporte de preparados de peixe, pelo que a generalidade das formas se considera destinada ao seu transporte. Ainda assim, a produção dos tipos Lusitana 3 e 9, de fundo plano, tem sido associada ao transporte de vinho.

\footnotetext{
${ }^{1}$ Para uma leitura das formas e tipologias anfóricas deverá ser consultar a bibliografia citada, assim como o site do Projecto Amphorae ex Hispania (http://amphorae.icac.cat/)
} 


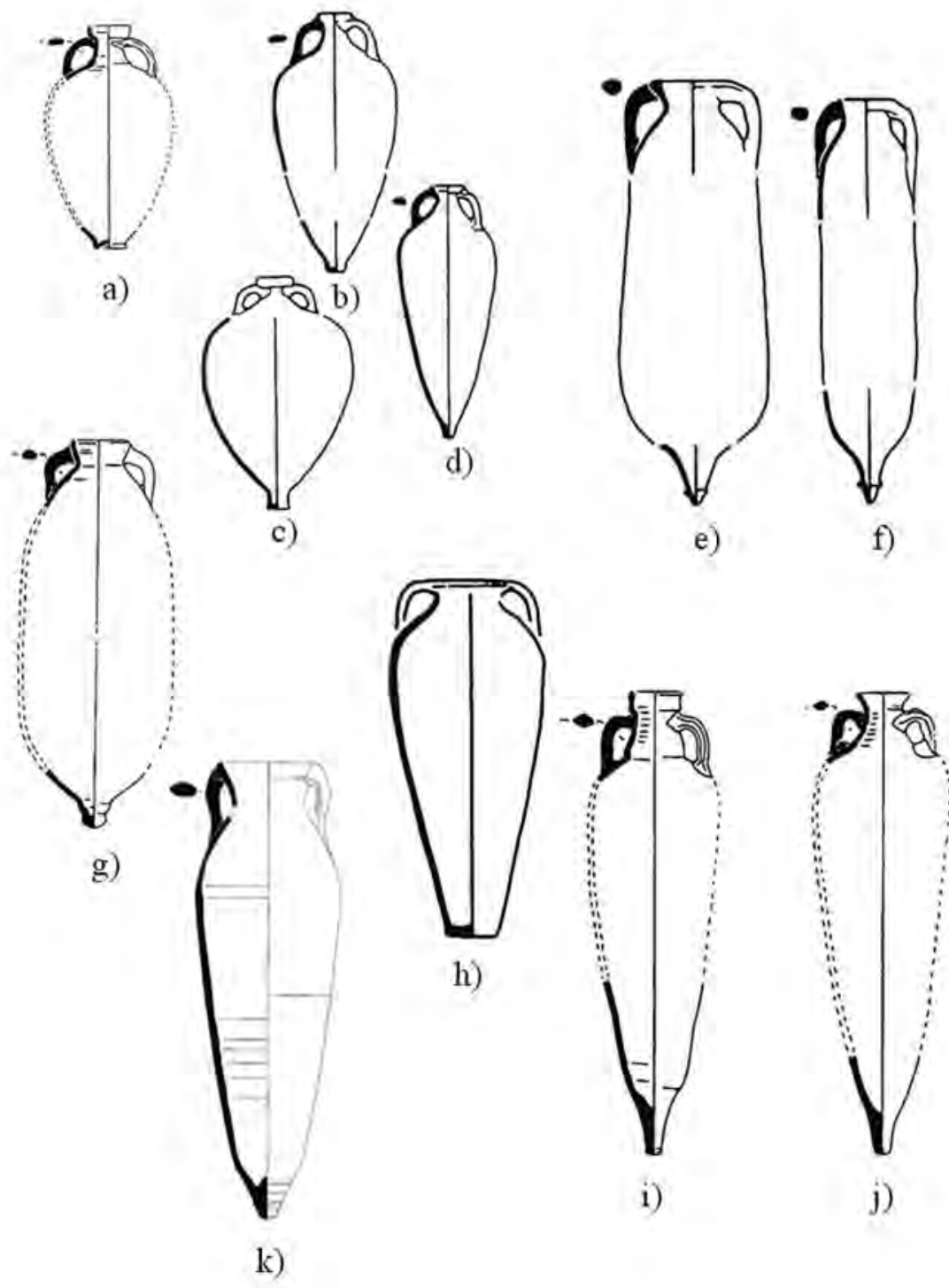

Figura 1 - Ânforas de produção Lusitana (séc. III a vI): a) Lusitana 3 do Pinheiro, Sado (Mayet e Silva, 1998 apud Fabião 2008); b), c) e d) Almagro 51c, e) Almagro 50 e f) Keay XVI do Porto dos Cacos e Quinta do Rouxinol, Tejo (Raposo, Sabrosa e Duarte, 1995 apud Fabião 2008); g) Keay 78 do Pinheiro, Sado (Mayet e Silva 1998 apud Fabião 2008); h) Lusitana 9 do Porto dos Cacos e Quinta do Rouxinol, Tejo (Raposo, Sabrosa e Duarte, 1995 apud Fabião 2008); i) e j) Almagro 51 a-b do Pinheiro, Sado (Mayet e Silva 1998, apud Fabião 2008); k) Sado 3 de Santarém (Arruda et al. 2005 apud Fabião 2008). 
De entre o conjunto de formas descritas, os tipos Almagro $51 \mathrm{C}$ e $51 \mathrm{a}-\mathrm{b}$ mantêm especial longevidade, constituindo as produções por excelência dos contextos algarvios (Bernardes 2008; Viegas 2009).

\section{A EXPORTAÇÃo DE PRODUTOS LUSITANOS PARA O MEditerRânEO: PROBLEMAS E DESAFIOS}

Os dados disponíveis, para o estudo da difusão de produtos lusitanos, resumem-se em grande parte ao estudo das ânforas, contentores marítimos por excelência. Assim, e tendo em consideração que a generalidade das ânforas produzidas na Lusitânia se destinava ao transporte de preparados piscícolas, é sobre a exportação desses produtos que focaremos a nossa análise. No entanto, uma análise do género acarreta um conjunto de dificuldades e limitações que procuraremos apresentar nas próximas linhas.

A conjugação do estudo da distribuição de artefatos em contextos terrestres com a localização de naufrágios é complexa. Parker analisou as suas limitações (Parker 2008). Empiricamente sabemos que a existência de um vazio na distribuição pode ser interpretado como uma efetiva ausência dos artefactos num determinado local, mas que pode igualmente corresponder à ausência de atividade arqueológica. Os métodos arqueológicos, baseados em mapas de distribuição de produtos, têm obviamente as suas limitações.

No campo da definição de rotas, os naufrágios constituem sem dúvida a fonte de informação mais completa. Fontes diretas no estudo da circulação de bens, os naufrágios não se apresentam, ainda assim, isentos de limitações. $O$ conjunto de naufrágios tradicionalmente associado à presença de ânforas de tipo lusitano, e ciclicamente replicado na bibliografia (Edmondson 1987; Mayet e Lopes 1990; Parker 1992; Mayet e Étienne 1993-94; Fabião 1996; 1997), constitui genericamente um conjunto de sítios subaquáticos mal caraterizados. A maioria são sítios de recolhas de superfície ocasionais, realizadas com pouco rigor científico e posicionados de forma deficiente. Nos quais nunca foi efectuada uma intervenção arqueológica sistemática e cujos resultados foram publicados de forma incompleta. O grande desafio será o da clarificação desses dados, o que passaria idealmente pela revisão da totalidade das ânforas identificadas nos contextos de naufrágio. A necessidade de reavaliação dos materiais tem por base o facto das formas anfóricas produzidas na Lusitânia não serem exclusivas da região. $\mathrm{O}$ estado actual dos conhecimentos permite-nos reconhecer a produção de formas análogas às produzidas na Lusitânia, designadamente as formas de maior difusão (Dressel 14 e as Almagro 50, 51 a-b e 51c), num conjunto de centros oleiros da região de Huelva, Baía Gaditana, Baía de Algeciras e Costa de Málaga. Existem ainda indícios da produção, das formas tardo-antigas, na Tarraconensis, na Tingitana e em E1 Mojón - Múrcia (Padilla Monge 2008: 358; Bernal Casasola 1998; Villaverde Vega 2001; Pons Pujol 2009: 121-123; Berrocal Caparrós 2012: 263-265). 
A economia marítima da Lusitânia apresenta-se mais complicada de compreender em comparação com a das províncias da Bética ou da Bizacena por exemplo, por se basear na exportação de preparados piscícolas. Produtos aos quais os hábitos epigráficos não se podem comparar ao do transporte de azeite ou vinho, e sobre os quais os autores clássicos praticamente não se pronunciaram. Por outro lado, continua a ser difícil individualizar as produções lusitanas, no vasto conjunto de dados publicados, sendo bastante vulgar encontrar classificações genéricas de origem, como sul-hispânica ou simplesmente da Península Ibérica. Mais do que fruto da dificuldade de identificação das produções lusitanas, principalmente ao nível das pastas, essas classificações generalistas enquadram-se no conjunto global do estudo da economia de importação, na qual a designação da macro-região de origem parece ser suficiente.

O “desconhecido" é também um factor limitativo, refletido na elevada percentagem de ânforas de forma e proveniência indeterminada, comum à generalidade dos contextos arqueológicos publicados.

Há ainda que ter em conta que os preparados de peixe terão constituído, na maioria das vezes, cargas secundárias enquadráveis num sistema de comércio livre e subsidiário, não comparável aos volumes de redistribuição do trigo, do azeite, do vinho, dos metais ou do mármore, promovidos pelo Estado com destino aos dois grandes mercados do mundo romano, Roma e os acantonamentos militares (Tchernia 2010). Assim, ter por objeto de estudo a distribuição de um produto minoritário no conjunto das trocas afigura-se difícil. Mais limitador parece ser estudar um produto originário da Lusitânia, cuja difusão se dilui no conjunto global das exportações do sul da Península Ibérica. No entanto, a sua identificação nas cargas naufragadas e nos contextos arqueológicos portuários, contribui, inegavelmente, para o conhecimento dos itinerários de circulação desses mesmos produtos. Ainda que, por outro lado, se apresentem dificuldades ao nível da comparação de percentagens de materiais arqueológicos de contextos e cronologias distintas (Reynolds 2010: 137).

Para além das limitações relativas à quantificação da produção, abordadas por Andrew Wilson (Wilson 2006), deparamo-nos com outro problema, o do desconhecimento do valor comercial dos produtos. Ou seja, o mesmo contentor anfórico teria um valor comercial seguramente diferente consoante o seu conteúdo, peixe salgado ou garum por exemplo.

Concluímos este ponto acrescentando uma limitação de fundo, o fato do estudo da economia da Antiguidade Tardia sofrer um défice de atenção se comparado com o dos períodos Republicano e Alto-Imperial. Para esse fato em muito tem contribuído o grande percentual de naufrágios entre o século i a.C. e o I d.C. registada no Mediterrâneo (Parker 1992), assim como a ideia pré-concebida de colapso das redes comerciais associadas à queda do Império Romano do Ocidente. No entanto, e ainda que as evidências apontem para uma efectiva diminuição do volume de bens transacionados, os produtos continuam a circular entre a esfera ocidental e oriental do Mediterrâneo. 


\section{Rotas, Cargas e Naufrágios: Os caminhos da exportação dos Prepa- RADOS DE PEIXE LUSITANOS}

Ainda que se considere que, pelo menos durante os séculos I e II, a distribuição de preparados de peixe tenha sido em geral independente da do azeite, os produtos piscícolas da Bética parecem ter beneficiado das redes de distribuição e navegação ao serviço da annona, quer no Mediterrâneo, quer no contexto Atlântico (Reynolds 2010 e Carreras Monfort 2000). A produção piscícola lusitana terá garantidamente, a par da sua congénere bética, aproveitando as rotas de abastecimento estatal com destino à cidade de Roma. Os produtos piscícolas do ocidente peninsular, entre os meados do século I e o século in d.C., seguiam em direcção ao porto de Ostia, em embarcações que navegavam ao largo das Ilhas Baleares e da Sardenha, atravessando o Estreito de Bonifácio. Os naufrágios de San Antonio Abad/Grum de Sal (Vilar-Sancho e Mañá 1964; 1965) e Punta Sardegna A (Porqueddu 2013) dão-nos conta da existência de cargas maioritárias de ânforas Dressel 14 lusitanas; enquanto casos como os de La Balise des Lavezzi, Lavezzi 1 e Lavezzi 3 (no Estreito de Bonifácio) nos dão conta de cargas mistas que incluem produtos piscícolas béticos e provavelmente lusitanos, associados a lingotes e/ou a ânforas olearias Dressel 20 béticas (Bebko 1971; Liou 1990 e Parker 1992).

A partir do século III d.C., os produtos lusitanos continuam a chegar aos mercados de Roma através da rota descrita, no entanto durante a Antiguidade Tardia as ânforas lusitanas atingem paragens mais meridionais, tais como a Sicília. A identificação de cargas onde as ânforas lusitanas surgem associadas a produtos norte-africanos, sugere a sua circulação nas rotas estabelecidas entre os portos africanos, como Cartago, e a península itálica ou o sul da Gália.

Ainda assim, entre meados do século iII e inícios do IV, as ânforas lusitanas continuavam a circular, na direcção Oeste-Este em direcção aos portos de Roma, em embarcações com cargas maioritariamente hispânicas ou provenientes de portos localizados no sul da Península Ibérica. São exemplos disso os naufrágios de Cabrera III (Bost et al. 1992) e Punta Ala A (Dell'Amico e Pallarés 2006), compostos por cargas mistas de ânforas piscícolas e olearias béticas (Dressel 20), ânforas norte-africanas (Africanas II) e ânforas lusitanas do tipo Almagro 51c.

Se durante o Principado os produtos piscícolas béticos dominam os mercados mediterrâneos ocidentais (Dressel 7-11 e Beltrán II), o registo arqueológico diz-nos que, durante a Antiguidade Tardia, as ânforas piscícolas lusitanas e norte africanas são muito mais comuns (Carreras Monfort 2010: 18), o que evidencia um maior potencial nos mercados. Ao que tudo indica as exportações de conservas de peixe béticas e lusitanas, transportadas em ânforas Almagro 51c, continuaram a chegar a Roma em quantidades apreciáveis até 420 d.C. (Padilla Monge 2008: 363). 
Os naufrágios de Punta Vecchia 1 e Fontanamare A/Gonnesa Sito A evidenciam a existência de cargas aparentemente maioritárias de ânforas lusitanas do tipo Almagro 51c, acompanhadas por contentores norte-africanos (Africana II), também eles associados ao transporte de preparados de peixe, e terra sigillata clara de produção tunisina (Leroy de La Brière 2006: 87; Leroy de La Brière e Meysen 2007: 88-89; Salvi e Sanna 2000; Dell'Amico, Faccena e Pallarés 2001-2002).

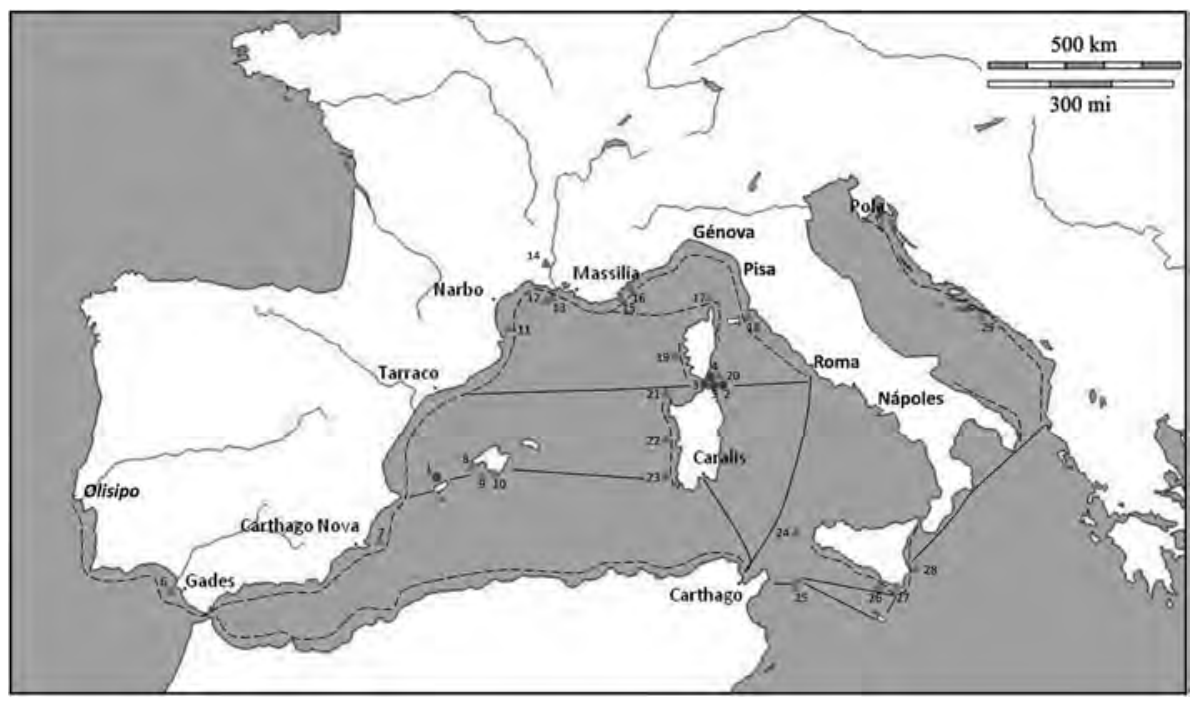

Figura 2 - Sítios de naufrágio referidos no texto e rotas de circulação das ânforas lusitanas no Mediterrâneo Ocidental. Alto Império: 1- San Antonio Abal/Grum de Sal; 2 - Punta Sardegna A; 3 - La Balise des Lavezzi; 4 - Lavezzi 1 e 5 - Lavezzi 3. Antiguidade Tardia: 6 - Sancti Petri; 7 - Escolletes 1; 8 - Cap Blanc; 9 - Cabrera I; 10 - Cabrera III; 11 - Port-Vendres 1; 12 Planier 7; 13 - Catalans; 14 - Arles-Rhône 7; 15 - Pampelonne; 16 - Chrétienne D; 17 - Punta Vecchia 1; 18 - Punta Ala A; 19 - Porticcio A; 20 - Sud-Lavezzi 1; 21 - Cala Reale A; 22 Mandriola A; 23 - Fontanamare A/Gonnesa; 24 - Levanzo 1; 25 - Scauri (Ilha de Pantelleria); 26 - Femina Morta; 27 - Randello; 28 - Marzameni F; 29 - Sobra.

A distribuição geográfica dos naufrágios com ânforas lusitanas, entre os meados do século III e os inícios do século v, concentra-se em cinco grandes áreas: as Baleares, a costa ocidental da Sardenha, o Estreito de Bonifácio, a costa da Gália e a Sicília.

Da sua localização podemos depreender a manutenção da rota Oeste-Este que parte do extremo ocidente da Península Ibérica em direcção aos portos de Roma, como nos indicam os naufrágios de Cap Blanc, Cabrera I, Cabrera III, Mandriola A, Cala Real A e Sud Lavezzi I. A existência de produtos africanos a bordo dos três primeiros pressupõe a sua reunião aos hispânicos, num dos portos 
do sul da Hispânia, provavelmente Cádis. Os naufrágios de Sud Lavezzi I (Liou 1982) e Cala Real A (Spanu 1997 e Gasperetti 2012), datados dos finais do século IV e inícios do $\mathrm{V}$, apresentam cargas muito idênticas, onde predominam as formas lusitanas Almagro 50, 51 a-b, 51c, e exemplares da forma Sado 3 no caso do segundo.

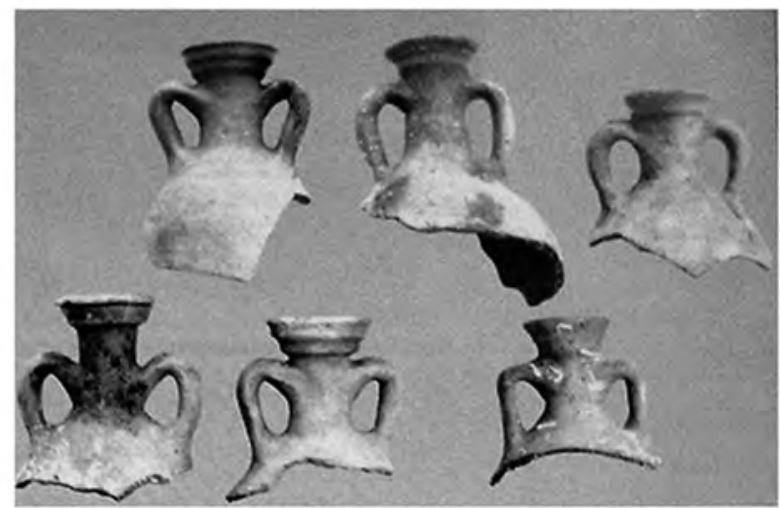

a)
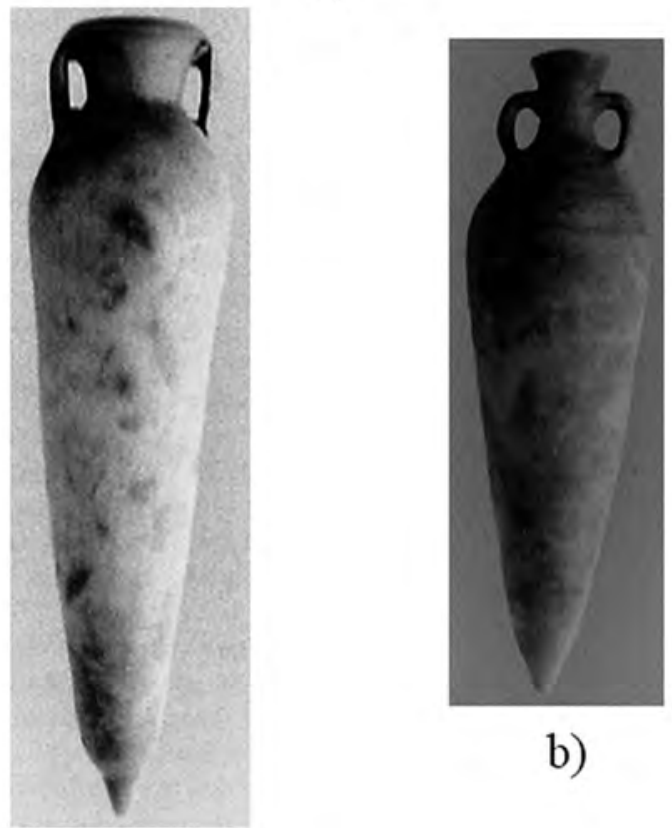

b)

c)

Figura 3 - Ânforas lusitanas do naufrágio de Cala Real A (Spanu 1997): a) e b) formas Almagro $51 \mathrm{a}-\mathrm{b}$; c) forma Sado 3. 

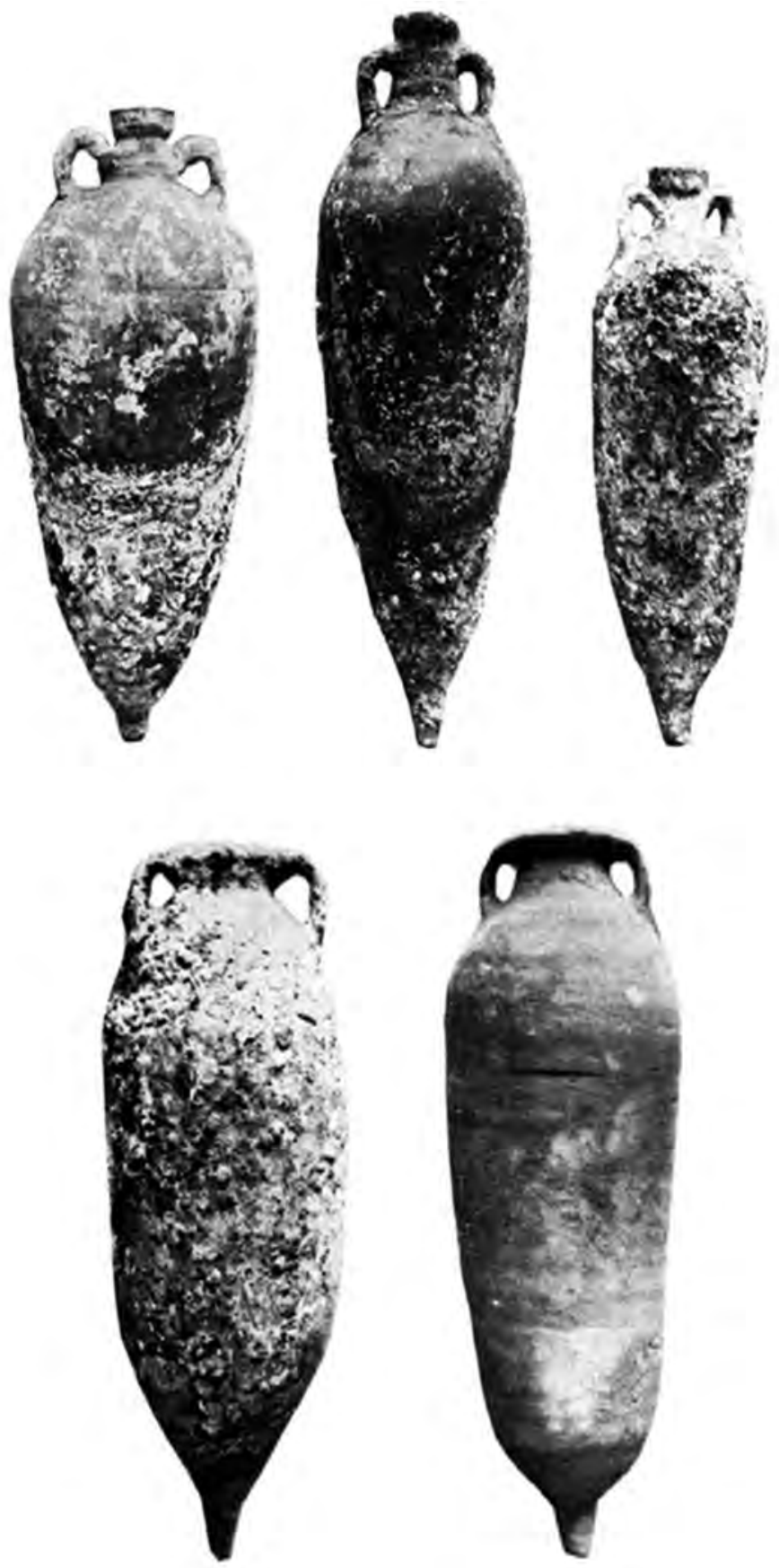

Figura 4 - Ânforas lusitanas do naufrágio de Sud-Lavezzi I (Liou 1982). 
A presença, em alguns casos maioritária, de ânforas de proveniência africana nos naufrágios da costa da Gália - Pampelonne, Planier 7 e Arles-Rhône 7 (Lequément 1976: 177-188; Benoit 1962: 157-159; Long e Duperron 2011) - às quais se juntam poucos exemplares de ânforas piscícolas sul-hispânicas (Almagro $50,51 \mathrm{c}$ e $51 \mathrm{a}-\mathrm{b})$ coloca dúvidas relativamente à rota através da qual esses produtos aí chegaram. Podemos conceber a sua chegada através de rotas de redistribuição provenientes de Roma, através da rota Roma-Arles, anteriormente referida. Outra alternativa, provavelmente menos plausível, serão as rotas de cabotagem ao longo das costas de Sardenha e da Córsega.

Contrariamente a esse fluxo de circulação, as ânforas lusitanas terão chegado ao litoral da Gália, através de rotas de distribuição provenientes da costa continental hispânica, em possível articulação com as Baleares. Os naufrágios de Port-Vendres I, Chrétienne D e Catalans (Liou 1973; 1974; Parker 1992; Joncheray e Brandon 1997: 121-135) nos quais as ânforas sul-hispânicas piscícolas são maioritárias, surgindo acompanhadas por uma carga secundária de ânforas norte-africanas e/ou de sigillata clara D. Estes naufrágios pressupõem uma junção de carga num dos portos do sul da Península Ibérica, até onde os produtos africanos terão sido encaminhados por meio de rotas ao longo da costa do Norte de África, no sentido Este-Oeste.

O naufrágio Punta Vecchia 1, localizado no Cap Corse, documenta a passagem de um navio com uma carga maioritária de ânforas lusitanas Almagro 51c, acompanhada por ânforas Africanas IIB e IID (Leroy de La Brière e Meysen 2007: 88-89). A sua localização ajusta-se às rotas provenientes da Península Ibérica, que costeando a costa da Gália entram no Alto Tirreno, dobrando o Cap Corse, muito provavelmente com destino aos portos de Roma ou ao Norte da Península Itálica.

A presença de ânforas lusitanas nos registos arqueológicos tardo-antigos de Pisa (Costantini 2010: 331-332), nos horrea de Vada Volaterrana (Menchelli e Pasquinucci 2004: 235), em Génova (Melli 2004: 9 e 11) e no naufrágio de Punta Ala A (Dell'Amico e Pallarés 2006) documentam a sua circulação nos circuitos comerciais e rotas de navegação do Alto Tirreno e Mar da Ligúria.

De mais difícil interpretação, no que concerne à rota percorrida, é o naufrágio de Porticcio A, localizado na costa ocidental da Córsega, datado do século III. A carga, bastante heterogénea, inclui ânforas com proveniência do mediterrâneo ocidental e oriental, sigillata clara $\mathrm{C}$, cerâmica comum e de cozinha africana, mortaria, uma lucerna, mais de 100 objectos em vidro e variados fragmentos de esculturas em mármore (Alfonsi 2008). A carga de ânforas é na sua grande maioria constituída pelo tipo Kapitan II, seguida de uma menor percentagem de Africanas II e Kapitan I. A grande variedade anfórica inclui ainda os seguintes tipos minoritários: Africana I, Forlimpopoli, Agora M 254, Almagro 51C, Almagro 50, Dressel 20, Dressel 23, Agora F65/66, Crétoise 2, Dressel 30, Dressel 28, Beltrán 72, Egípcia Romana, Empoli, Tripolitana, Peacock \& Williams 60 e 

no Mediterrâneo Ocidental (Séculos III a VI) - Dados preliminares

Zemer 57, para além de outros tipos indeterminados. De entre os fragmentos anfóricos atribuíveis aos tipos lusitanos registam-se: 4 fragmentos de Almagro 51c e 2 fragmentos associáveis ao tipo Almagro 50/Keay XVI, de provável produção bética (Alfonsi 2005; 2010).

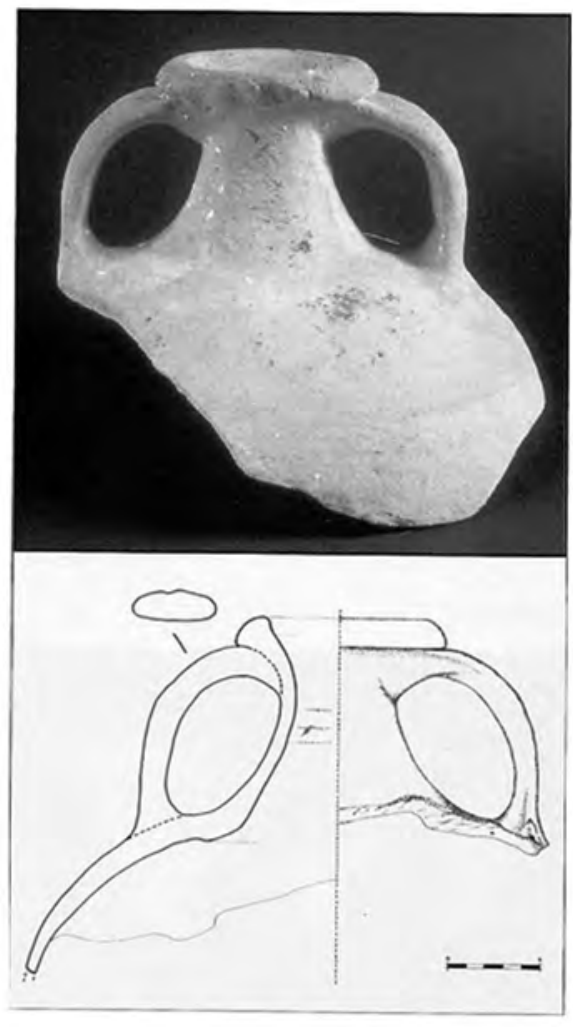

a)

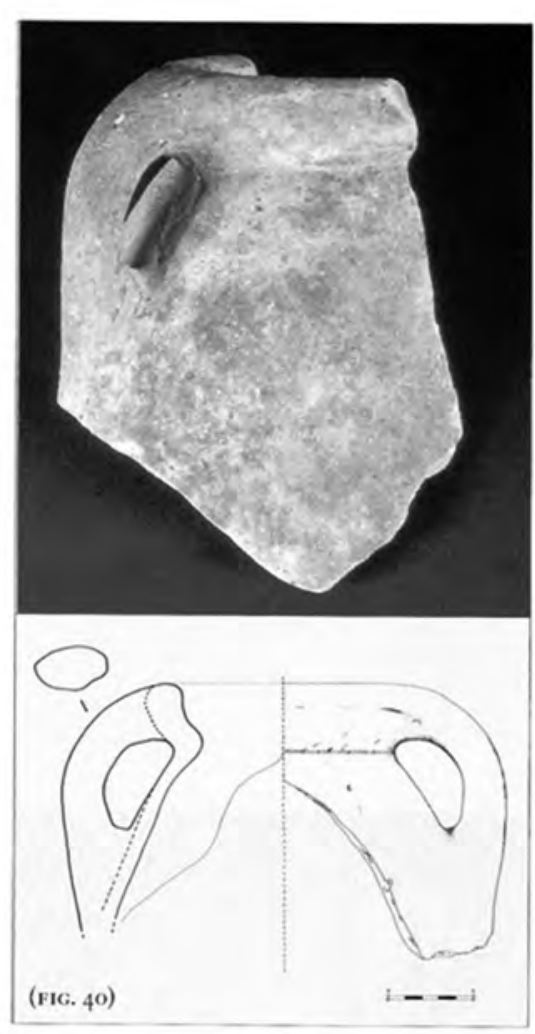

b)

Figura 5 - Ânforas lusitanas do Fontanamare A/Sítio A de Gonnesa (Salvi e Sanna 2000); a) Almagro 51c; b) Keay 78 .

O naufrágio de Fontanamare A/Gonnesa A (Salvi e Sanna 2000; Dell'Amico, Facenna e Pallarés 2001-2002), datável dos finais do século in e inícios do século Iv, no qual as ânforas lusitanas Almagro 51c e Keay 78 estão documentadas, conjuntamente com Africanas IID e numerosos fragmentos de sigillata clara $\mathrm{D}$, parece sugerir a existência de uma reunião de carga num dos portos do Norte de África, ou até mesmo no sul da Sardenha, em Cagliari por exemplo. A Sardenha, pelo seu papel geo-estratégico no Mediterrâneo, no caminho das rotas Oeste-Este e Sul-Norte, é local de passagem obrigatório para os produtos piscícolas lusitanos. Presentes desde o século I d.C., as ânforas de produção 
lusitana ganham especial destaque a partir do século iII, conjuntamente com as produções africanas. Assim parecem indicar as percentuais registadas em Turris Libisonis, Cagliari e Nora (Piccardi e Nervi 2013; Nervi 2014).

Os naufrágios registados na costa oriental da Sićlia (Marzameni F, Femina Morta e Randello) colocam as ânforas lusitanas Almagro 50 e 51c no caminho do mediterrâneo central e oriental conjuntamente com as produções anfóricas africanas e a sigillata de produção tunisina (Parker, 1981; 1989; 1992).

Para além de destinos mais orientais, como Beirut, onde as ânforas lusitanas estão razoavelmente bem documentadas nos séculos IV e V (Reynolds 2010: 42-43), as lusitanas terão circulado ao longo das costas adriáticas. Ao naufrágio de Sobra, onde foram identificadas ânforas de tipo Almagro 50 (Parker 1992), deveremos acrescentar outros registos, tais como: a identificação de dois exemplares de Almagro 50, num contexto de armazém dos finais do século v, em Pula (Croácia) (Starac 2014: 177-178); e os registos residuais das formas Almagro 51 a-b e 51c em Egnazia (Puglia, Itália), datados dos finais do século iv e inícios do v (Berloco et al. 2014: 209).

Os resultados publicados das escavações britânicas em Cartago não individualizam as produções regionais no conjunto global de importações da Península Ibérica. No entanto, sabemos pelos dados de Reynolds que as produções lusitanas se encontram documentadas nas termas de Bir El Jebbana, em contextos dos finais do seculo I até ao V (Reynolds 2010: 44).

A identificação de pelo menos um exemplar de Almagro 51c lusitana no naufrágio de Scauri, na Ilha de Pantelleria, coloca questões interessantes. O naufrágio, atribuído à primeira metade do século v, apresenta um carregamento na sua quase totalidade constituído por cerâmica de cozinha de Pantelleria (77\%). Surgem depois em pequenas percentagens as cerâmicas comum, de cozinha e de mesa africana (sigillata), as lucernas e as ânforas, de ente as quais de identificaram produções da África Proconsular, Zeugitana, Bizacena, Tripolitana, Orientais (Creta, Ásia Menor, Palestina) e Ocidentais, nas quais se incluem exemplares Lusitanos e provavelmente béticos (Keay XV e XIX) (Baldassari 2009: 92 e 108). A presença de ânforas lusitanas numa embarcação que se imagina naufragada à saída do porto de origem, mas que apresenta uma carga tão diversificada, documenta a circulação dos produtos piscícolas lusitanos no seio do complexo sistema de rotas entre o Oriente e o Ocidente, no qual a região marítima entre o sul da Sicília e o porto de Cartago terá desempenhado um papel importante.

Os dados por nós recolhidos, até ao momento, permitem-nos concluir que, apesar da sua presença residual na maioria dos contextos analisados, as ânforas de preparados de peixe lusitanas apresentam uma maior difusão geográfica durante a Antiguidade Tardia. Demonstrando uma grande capacidade no abastecimento dos mercados de maior proximidade, como Hispallis, onde representam mais de $30 \%$ dos materiais anfóricos tardo antigos, prevalecendo sobre as importações africanas e orientais, sendo apenas menos numerosas que as produções da própria 
Bética (Garcia Vargas 2007: 347). A mesma tendência é observável no naufrágio de Escolletes 1 (Múrcia), datável dos inícios do seculo IV, e onde as ânforas lusitanas, com destaque para a forma Almagro 51c, são maioritárias (Cerezo Andreo 2011) .O autor documenta ainda os tipos Almagro 50, Keay 78 e imitações da forma Dressel 28 de pastas lusitanas (Cerezo Andreo 2011: 62 a 76).

A presença de ânforas lusitanas ao longo da fachada mediterrânea da Península Ibérica, em locais como Valência, Tarraco ou Barcino, parece indicar-nos a sua circulação em rotas que percorreriam esse troço de mar em direção ao sul da Gália.

Em Tarraco, entre os finais do século III e o fim do século IV, as ânforas são maioritariamente originárias da Hispânia (Tarraconense, Lusitânia e Bética) e da África (Macias i Solé e Remolà Vallverdú 2005). Durante o século V as grandes zonas abastecedoras continuam a ser a Hispânia e a África, mas a novidade reside no notável aumento de ânforas procedentes do Mediterrâneo oriental, um fenómeno que caracteriza os registros arqueológicos deste período noutras cidades do Mediterrâneo Ocidental (Remolà Vallverdú 1998: 807).

As formas Almagro 50 e 51 de produção lusitana foram documentadas em Barcino, em níveis dos séculos iv e v, com alguns exemplares a poderem ser atribuídos aos níveis dos séculos vieviı.No entanto, asuapresençaésempremuitoresidual,compercentuais inferiores aos 5\% do total de ânforas importadas (Carreras Monfort 2012).

As formas Almagro 51 a-b e 51c lusitanas estão presentes, em níveis do século v, em Lyon (Vallet, Lemaître e Schmitt 2010: 210), em Arles e em Narbonne (Alessandri, Pieri, Sanchez 1998: 121). Cidade na qual as relações económicas com as províncias da vizinha Hispânia, durante a Antiguidade Tardia, parecem ter sido muito mais frequentes do que em Marselha (Alessandri, Pieri, Sanchez 1998: 121), onde predominam desde meados do século $\mathrm{V}$ as ânforas orientais seguidas das africanas. Tendência que só se altera no decurso do século vi com o aumento das produções africanas, situação que se mantém até aos finais do século viI (Bonifay e Piéri 1995: 116).

A presença de ânforas lusitanas em Roma, em contextos pós-severianos, tem sido documentada em diversos contextos ${ }^{2}$. No Palatino, na cripta de San Bonaventura, num contexto da segunda metade do século III, as formas Almagro 51 a-b e 51c correspondem a 5\% do conjunto anfórico (Caragnani e Pacetti 1989). A identificação de lusitanas foi igualmente registada num contexto datado entre 290 e 312/315 d.C., correspondente a uma domus localizada na zona norte-ocidental do Palatino (Peña 1999). Contemporâneas são as formas lusitanas identificadas num contexto de entulheira da fundação do Arco de Constantino (Zeggio e Rizzo 1998). Os contextos de escavação, datados entre a segunda metade do século iv e a segunda metade do v, no templo de Magna Mater, no

${ }^{2}$ Agradecemos ao Doutor Giorgio Rizzo a compilação bibliográfica dos dados da cidade de Roma. 
Palatino, documentam igualmente ânforas lusitanas dos tipos Almagro $51 \mathrm{a}-\mathrm{b}$ e 51c (Panella e Saguì 2001 e Panella et al. 2011). Os tipos lusitanos foram ainda identificados, na capital do Império, num conjunto de outros contextos do século v, entre os quais a Basilica Hilariana (Bertoli e Pacetti 2011), a igreja de Santo Stefano Rotondo (Rizzo 2009: 270-272), e a insula sondada na área de S. Cecília em Trastavere (Auriemma 2004: 201-203).

A identificação de ânforas de tipo lusitano, nos mais variados contextos arqueológicos do mundo romano, carrega consigo a dificuldade acrescida da sua classificação, na base da sua não exclusividade produtiva, como anteriormente referimos. Nesse sentido, concluímos o presente artigo com a identificação sumária de alguns exemplos dessas classificações ambíguas.

O sítio de Sancti Petri (Baía de Cádiz), documentado desde 1992, revelou a presença de um núcleo de materiais datáveis entre a segunda metade do século iv e a primeira metade do v; de entre os quais figuram ânforas de tipo Almagro 50 e 51, ânforas africanas e sigillata clara. Das figuras publicadas é possível identificar os tipos Sado 3 lusitano, Keay XIX/Almagro 51 a-b e Keay 25 africana (Alonso Villalobos et al. 1994: 47, fig. 4 e 5). O naufrágio contribui para a afirmação da continuidade do comércio gaditano até à primeira metade do século v d.C.; atestando assim o pleno funcionamento do porto de Gades nessa época (Bernal Casasola 2004: 47).

A zona costeira de Port-Vendres continua a revelar o seu enorme potencial arqueológico subaquático com a regular descoberta de novos sítios de naufrágio. No limite ocidental de Anse Béar, numa zona rochosa, foi realizada, em 2005, uma sondagem ( $\left.{ }^{\circ} 20\right)$ que revelou a presença de material cerâmico do século III d.C., entre o qual se encontra uma ânfora de tipo Almagro 50 e uma de tipo Almagro 51c de origem lusitana ou bética. (Castellvi e Salvat 2007: 3) Foi igualmente recuperada uma pança de um tipo indeterminado que poderá corresponder a uma Lusitana 3 ou Almagro 51c lusitana.

Em 2006, numa campanha de prospeção com ROV, foi localizado a 94m de profundidade o sítio de Levanzo I, a Norte da pequena ilha de Levanzo localizada a Oeste da Sicília. De entre o conjunto de ânforas identificadas, que são na sua grande maioria ânforas tunisinas de tipo Africana I e II, surge um exemplar do tipo Almagro 51c cujos autores apresentam como de provável proveniência Lusitana, Bética ou Norte Africana (Royal e Tusa 2012: 40).

\section{Conclusões}

Se cruzarmos a cartografia dos achados subaquáticos com a das rotas mediterrânicas na Antiguidade $\operatorname{Tardia}^{3}$ saltam à vista uma série de concentrações

${ }^{3}$ Para o estudo das rotas de navegação na Antiguidade consultámos essencialmente a obra de Pascal Arnaud (2005). 
A exportação de produtos lusitanos na Antiguidade Tardia: rotas, cargas e naufrágios no Mediterrâneo Ocidental (Séculos III a VI) - Dados preliminares

geográficas. Estas, não podendo ser alienadas das condições difíceis de navegação dos locais, indicam-nos acima de tudo locais de cruzamento de cargas e rotas, mas também entrepostos portuários de redistribuição e consumo.

Apesar da multiplicação de intervenções arqueológicas dos últimos anos, que em muito tem contribuído para o crescente conhecimento das unidades de produção de preparados de peixe e das olarias produtoras de ânforas, a elas associadas, estamos ainda longe de uma total compreensão das dinâmicas, do volume e das cronologias da produção e exportação. Todavia, estamos convencidos que os dados registados em terra, devidamente articulados com os dados subaquáticos, permitirão num futuro próximo aferir algumas dinâmicas comerciais e compreender melhor as rotas e fluxos económicos nos quais as ânforas lusitanas circularam. 


\section{Bibliografia}

ALONSO VILLALOBOS, C. ; GALLARDO ABÁRZUZA, M. ; GARCIA RIVERA, C. e MARTI SOLANO, J. (1994) - Prospecciones Arqueológicas Subacuáticas en Sancti-Petri. Anuario Arqueológico de Andalucia 1994, Actividades Sistemáticas, Sevilha, p. 44-48.

ALESSANDRI, Patrice; PIERI, Dominique e SANCHEZ, Corinne (1998) Note sur un lot d'amphores du Ve Siècle de notre ère à Narbonne (Aude). In : Rivet e Saulnier (Eds.), Importations d'anphores en Gaele du Sud, du règnes d'Auguste à l'Antiquité tardive, Actes di Congrès d'Istres, Marselha, p. 117-122.

ALFONSI, H. (2005) - Fouille Archeologique Sous-Marines de l'épave de Porticcio, Rapport 2005, Marseille, Département des recherches archéologiques subaquatiques et sous-marines. Não publicado

ALFONSI, H. (2008) - L'épave de Porticcio. In : Stantari (Ed.) Histoire naturelle e culturelle de la Corse, n. ${ }^{\circ} 12$.

ALFONSI, H. (2010) - Fouille Archeologique Sous-Marines de l'épave de Porticcio, Rapport 2010, Marseille, Département des recherches archéologiques subaquatiques et sous-marines. Não publicado.

ARNAUD, Pascal (2005) - Les routes de la navigation antique-Itinéraires en $M e-$ diterranée. Paris.

AURIEMMA, R. (2004) - La ceramica della fase del battistero paleocristiano. In: Parmegiani; Pronti (Ed.) Santa Cecilia in Trastevere. Nuovi scavi e ricerche (Monumenti di antichità cristiana, II serie, XVI), Vaticano, p. 197-230.

BALDASSARI, Roberta (2009) - Il materiale del carico del relitto: analisi tipologica e quantitativa della ceramica locale da fuoco e Le anfore da trasporto. In: La Rocca; Tusa, Zangara (Ed.) Il relitto tardo-antico di Scauri a Pantelleria, Palermo.

BEBKO, W. (1971) - Les épaves antiques du Sud de la Corse. Cabiers Corsica 1-3, Bastia.

BENOÎT, F. (1962) - Nouvelles épaves de Provence (III). Gallia, 20.

BERLOCO, V.; CONTE, R.; FOSCOLO, M.; GIANNICO, V.; PALMISANO, D.; PIGNATARO, M.; SHIAVARIELLO, G. (2014) - Stratigraphy of 'tips': about some 'closed' contexts from Egnazia (Fasano-Italy). Actas $28^{\text {th }}$ Congress of the Rei Cretariae Romanae Faustores, p. 203-218.

BERNAL CASASOLA, D. (1998) - Anforas del bajo imperio en Baetica y Tingitana: estado de la cuestión y primeras aportaciones arqueológicas. 
A exportação de produtos lusitanos na Antiguidade Tardia: rotas, cargas e naufrágios no Mediterrâneo Ocidental (Séculos III a VI) - Dados preliminares

In: Teja; Pérez González (Coord.) Congreso Internacional La Hispania de Teodosio: actas, Vol. 2.

BERNAL CASASOLA, D. (2000) - Las ánforas béticas en los confines del imperio. Primera aproximación a las exportaciones a la pars Orientalis. Ex Baetica amphorae. Conservas, aceite y vino de la Bética en el imperio romano. Congreso internacional,. Actas, p. 935-988.

BERNAL CASASOLA, D. (2004) - Comercio, rutas y navegación en la Hispania meridional tardorromana (ss. III-VII d.C.). Una perspectiva desde la arqueología litoral. In: De Maria; Turchetti, (eds.), Rotte e porti del Mediterraneo dopo la caduta dell'Impero roma d'Occidente, Continuità e innovazioni tecnologiche e funzionali, IV Seminario ANSER, p. 33-64.

BERNAL CASASOLA, D. (2008) - El final de la industria pesquero-conservera en Hispania (ss. v-vil d.C.) entre Obispos, Bizancio y la evidencia arqueológica. In: Napoli, J. (ed.) Ressources et activités maritimes des peuples de l'Antiquité. Les Cahiers du Littoral, 2 (6), p. 31-58.

BERNAL CASASOLA, D. (2010) - Iglesia, producción y comercio en el Mediterráneo tardoantiguo. De las ánforas a los talleres eclesiásticos. In: Menchelli; Santoro; Pasquinucci; Guiducci (Eds), LRCW3 Late Roman Coarse Wares, Cooking Wares and Amphorae in the Mediterranean: Archaeology and archaeometry. Comparison between western and eastern Mediterranean, Volume I, BAR 2185.

BERNARDES, J. P. (2008) - O Centro Oleiro do Martinhal. Xelb 8 (Actas do $5^{\circ}$ Encontro de Arqueologia do Algarve), Vol. 1, p. 191-212.

BERTOLDI, T.; PACETTI, F. (2010) - Materiali di V secolo dalla Basilica Hilariana sul Celio: analisi tipologica delle ceramiche comuni. In: Menchelli; Santoro; Pasquinucci; Guiducci (Eds), LRCW3 Late Roman Coarse Wares, Cooking Wares and Amphorae in the Mediterranean: Archaeology and archaeometry. Comparison between western and eastern Mediterranean, Volume I, BAR 2185, p. 433-445.

BERROCAL CAPARRÓS, M. del C. (2012) - Producciones anfóricas en la costa meridional de Carthago-Spartaria. In: Bernal Casasola; Ribera i Lacomba (eds), Cerámicas hispanorromanas II - Producciones regionales. Cádiz, p.255-277.

BONIFAY, Michel ; PIERI, Dominique (1995) - Amphores du Ve au VIIe s. à Marseille: nouvelles données sur la typologie et le contenu. Journal of roman archaeology, 8 p. 94-120.

BOST, J. P.; CAMPO, M.; COLLS, D.; GUERRERO, V. y MAYET, F. (1992) - L'épave Cabrera III (Majorque). Échanges commerciaux et circuits monétaires 
au milieu du IIIe siècle après Jésus-Christ. Publications du Centre Pierre Paris, 23. Paris.

CARIGNANI, A. e PACETTI, F. (1989) - Anfore tardo-antiche dagli scavi del Palatino. Amphores Romaines et Histoire Economique: dix ans de recherche, Sienne, , Rome, p. 610-615.

CARRERAS MONFORT, C. (2000) - Economia de la Britannia Romana: La Importación de Alimentos, Collecció Instrumenta 8, Barcelona.

CASTELLVI, Georges e SALVAT, Michel (2007) - Un trésor monétaire du III e s. ap. J.C., découvert dans les eaux de Port-Vendres (Pyrénées-Orientales). Domitia, n. 8 .

CEREZO ANDREO, F. (2011) - La colección material del yacimiento subacuático de Escolletes. Arqueología Náutica y Dinámicas Comerciales em el Sureste Ibérico en Época Bajo Imperial. Trabalho Final de Master, Universidade de Murcia. Não publicado.

CONSTANTINI, A. (2010) Pisa - Via Marche: le amphore della necropoli tardoantica. In: Menchelli; Santoro; Pasquinucci; Guiducci (Eds), LRCW3 Late Roman Coarse Wares, Cooking Wares and Amphorae in the Mediterranean: Archaeology and archaeometry. Comparison between western and eastern Mediterranean, Volume I, BAR 2185, p. 329-336.

DELL'AMICO, P; FACENNA, F. e PALLARÈS, F. (2001-2002) - Fontanamare (Cagliari). Il relitto 'A'. Bullettino di Numismatica 36-39, p. 9-151.

DELL'AMICO, P e PALLARÈS, F. (2006) - Il relitto "A" di Punta Ala. Roma.

DIAS DIOGO, A.M.D. (1987) - Quadro Tipológico das ânforas de fabrico lusitano. O Arqueólogo Português, Série IV, 5, p. 179-191.

EDMONDSON, J. C (1987) - Two industries in Roman Lusitania mining and garum production, Oxford: BAR IS 362.

ÉTIENNE, R. e MAYET, F. (1993-1994) - La place de la Lusitanie dans le commerce méditerranéen. Conimbriga 32-33, p. 201-218.

EXPOSITO ALVAREZ, J. A. e BERNAL CASASOLA, D. (2007) - Ánforas orientales en el extremo occidente: las importaciones de LR1 en el sur de Hispania. In: Bonifay; Tréglia (eds). LRCW2. Late Roman Coarse Wares, Cooking Wares and Amphorae in the Mediterranean: Archaeology and Archaeometry. Volumen I, BAR IS 1662.

FABIÃO, C. (1996) - Sobre a Tipologia das ânforas da Lusitânia. Ocupação Romana dos Estuários do Tejo e do Sado - Actas das primeiras Jornadas sobre Romanização dos Estuários do Tejo e do Sado. Lisboa, p. 371-390. 
A exportação de produtos lusitanos na Antiguidade Tardia: rotas, cargas e naufrágios no Mediterrâneo Ocidental (Séculos III a VI) - Dados preliminares

FABIÃO, Carlos (1997) - A Exploração dos Recursos Marinhos. Portugal Romano: a exploração dos recursos naturais. Lisboa.

FABIÃO, C. (2004) - Centros oleiros da Lusitania. Balanço dos conhecimentos e perspectivas de investigação. Actas del Congresso Internacional Figlinae Baeticae. Talleres alfareros y producciones cerámicas en la Bética romana (ss. II a.C. - VII d.C.), B.A.R, IS1266, p. 379-410.

FABIÃO C. (2008) - Las ánforas de Lusitania. In: Bernal; Ribera Lacomba (Eds.) Cerámicas hispanoromanas. Un estado de la cuestión. Actas del XXVI Congreso Internacional de la Asociación Rei Cretariae Romanae Fautores, p. $725-745$.

FABIÃO, C. (2009a) - O Ocidente da península Ibérica no século VI: sobre o pentanummium de Justiniano I encontrado na unidade de produção de preparados de peixe da Casa do Governador da Torre de Belém, Lisboa. ERA Apontamentos de Arqueologia e Património 4, p. 25-50.

FABIÃO, C. (2009b) - Cetárias, ânforas e sal: a exploração de recursos marinhos na Lusitania. Estudos Arqueológicos de Oeiras 17, p. 555-594.

FERNÁNDEZ FERNÁNDEZ, A. (2010) - Rías Baixas and Vigo (Vicus Eleni). In: Carreras Monfort; Morais (Eds.), The Western Roman Atlantic Façade: a study of economy and trade in the Mar Exterior. From the Republic to the Principate, BAR 2162, p. 229-237.

GARCÍA VARGAS, Enrique (2007) - Hispalis como Centro de consumo desde época Tardo Republicana a la Antiguedad Tardía. El testimonio de las ánforas. Anales de Arqueología Cordobesa 18, p. 317-360.

GARCÍA VARGAS, Enrique (2011) - Oriental trade in the Iberian Peninsula during Late Antiquity (4th-7th centuries AD). An archaeological perspective. New Perspectives on Late Antiquity. Cambridge, p. 76-117.

GASPERETTI, G. (2012) - L'attività del Servizio per l'Archeologia Subacquea della Soprintendenza per i beni archeologici per le province di Sassari e Nuoro. Un caso significativo. Erentzias, Volume I, p. 293-305

JONCHERAY, J. P. (1975) - Une épave du Bas Empire : Dramont F. Cahiers d'archéologie subaquatique, 4.

JONCHERAY, J. P. e BRANDON, Christopher (1997) - Deux épaves du Bas-Empire romain: Première partie: L'épave Chrétienne D. Cahiers d'archéologie subaquatique, 13, p. 121-35.

LAGÓSTENA BARRIOS, Lázaro (2001) - La producción de salsas y conservas de pescado en la Hispania Romana: (II a.C. - VI d.C.), Collecció instrumenta 11, Barcelona. 
LEQUEMENT,R.(1976)-Uneépave du Bas-Empire danslabaie de Pampelonne (presqu'île de Saint-Tropez). Revue archéologique de Narbonnaise Tome 9.

LEROY DE LA BRIERE, G. (2006) - Littoral de la Corse. Travaux et recherches archéologiques de terrain. Département des recherches archéologiques subaquatiques et sous-marines, Bilan Scientifique 2004, p. 87.

LEROY DE LA BRIÈRE, G. e MEYSEN, A (2007) - Littoral de la Corse. Travaux et recherches archéologiques de terrain. Bilan Scientifique do DRASSM 2005, p. 88 e 89.

LIOU, B. (1973) - Recherches archéologiques sous-marines. Gallia. Tome 31 fascicule 2, p. 571-608.

LIOU, B. (1974) - L'épave romaine de l'anse Gerbal à Port-Vendres. Comptes rendus, Academie des Inscriptions et Belles-Lettres, p. 414-433.

LIOU, B. (1982) - Direction des recherches archéologiques sous-marines. Gallia Tome 40 fascicule 2, p. 437-454.

LIOU, B. (1990) - Le commerce de la Bétique au Ier siécle de notre ère. Notes sur l'épave Lavezzi 1 Bonifacio, Corse du Sud. Archeonautica 10, p.125-155.

LONG, L. e DUPERON, G. (2011) - Le mobilier de la fouilee de l'épave romaine Arles-Rhône 7. Un navire fluvio-maritime du IIIe siècle de notre ère. SFECAG. Actes du Congrès d'Arles. 2-5 Juin 2011, p. 37-56.

LOPES, C. e MAYET, F. (1990) - Commerce Régional et Lointain des Amphores Lusitaniennes. Anforas lusitanas. Tipologia, produção, comércio. Coimbra, p. 295-303.

MACIAS I SOLÉ, J. M. e REMOLÀ VALLVERDÚ,J. A. (2005) - La cultura material de Tarraco-Tarracona (Hispania Tarraconensis-Regnum Visigothorum): cerámica común y ánforas. In: Gurt; Buxeda; Cau (Eds), LRCW 1. Late Roman Coarse Wares, Cooking Wares and Amphorae in the Mediterranean. Archaeology and Archaeometry. BAR IS 1340, p. 125-135.

MANTAS, Vasco Gil (1998) - Navegação, economia e relações interprovinciais: Lusitânia e Bética. Humanitas 50, p. 199-240.

MAYET, F. (2001) - Les amphores lusitaniennes. Céramiques Hellénistiques et Romaines 3, p. 277-293.

MELLI, Piera (2004) - The role of Genoa in the Mediterranean trade in Antiquity. In: Pasquinucci; Weski (Eds.), Close encounters: Sea- and Riverborne trade, port and hinterlands, ship construction and navigation in Antiquity, the Middle Ages and in Modern Time, BAR IS1283, p. 1-18.

MENCHELLI, S. e PASQUINUCCI, M. (2004) - Archeologia della redistribuizione nell'Etruria Settentrionale: il caso di Vada Volaterrana. 

no Mediterrâneo Ocidental (Séculos III a VI) - Dados preliminares

In: Malfitana; Poblome; Lund (Eds) Old Poterry in a new century. Innovative Prespectives in Roman Pottery Studies, Proccedings of the International Workshop, Catania 22-24 April 2004, Catania.

MORAIS, Rui (1998) - As Anforas da Zona das Carvalheiras. Contribuição para o Estudo das Anforas Romanas de Bracara Augusta. Cadernos de Arqueologia/ Monografias 8, Braga.

NERVI, C. e Piccardi, E. (2013) - Produzioni anforiche dalla Penisola Iberica in Sardegna. In: Bernal; Bustamante; Díaz; Sáez (Eds) - Hornos, talleres y focos de producción alfarera en Hispania, Monografías ex Officina Hispana 1, Actas do I Congreso Internacional de la SECAH ,Tomo II, p. 365-388.

NERVI,C. (2014) - La Sardinia tra Peninsula Iberica ed Africa immersa in un mare di sale. In: Botte; Leicht (Eds), Fish and Ships. Production et commerce des salsamenta durant l'Antiquité, BIAMA 17, Aix en Provence, p. 199-212 .

PADILLA MONGE (2008) - La ordenación territorial de la Bahía de Cádiz durante el Imperio Romano Tardío. Revista Atlántica-Mediterránea de Prehistoria y Arqueología Social 10, p. 365.

PANELLA, C. e SAGUI, L. (2001) - Consumo e produzione a Roma tra tardoantico e altomedioevo: le merci, i contesti. Roma nell'alto medioevo, settimane di studio del C.I.S.A.M., XLVIII, Spoleto, 2000, Spoleto, p. 757-820.

PANELLA, C.; SAGUİ, L.; CASALINI, M. e COLETTI, F. (2010) - Contesti tardoantichi di Roma: una rilettura alla luce di nuovi dati. In: Menchelli; Santoro; Pasquinucci; Guiducci (Eds), LRCW3 Late Roman Coarse Wares, Cooking Wares and Amphorae in the Mediterranean: Archaeology and archaeometry. Comparison between western and eastern Mediterranean, Volume I, BAR 2185, Volume I, p. 57-78.

PARKER, A. J. (1981) - Stratification and contamination in Ancient Mediterranean shipwrecks. The International Journal of Nautical Archaeology and Underwater Exploration 10, 4, p. 309-335.

PARKER, A. J. (1989) - Amphores Almagro 50 de l'épave de Randello (Sicile). École Française de Rome, 114, Rome.

PARKER, A.J. (1992) - Ancient shipwrecks of the Mediterranean and Roman Provinces. BAR IS 580.

PARKER, A.J. (2008) - Artifact Distribuitions and Wreck Locations: The Archaeology of Roman Commerce. In: R. L. Hohlfelder (Ed.) The Maritime World of Ancient Rome. Ann Arbor, p. 177-196.

PEÑA, J. Th. (1999) - The Urban Economy during the Early Dominate. Pottery evidence from the Palatine Hill (BAR IS 784), Oxford. 
PIERI, Dominique (2002) - Marchands Orientaux Dans L'économie Occidentale De L'antiquité Tardive. In: Rivet ; Sciallano (Eds.), Vivre, produire et échanger : reflects méditerranéens. Mélanges offerts à Bernard Liou, Montagnac (Archéologie et Histoire romaine 8), p. 123-132.

POMEY, P.; LONG, L.; LHOUR, M.; RICHEZ, F. e BERNARD, H., (1989) - Recherches sous-marines. Gallia Informations (1987-8).

PONS PUJOL, Lluís (2009) - La Economía de la Mauretania Tingitana (s. I-III d.C.): aceite, vino y salazones. Colleccío Instrumenta 34, Barcelona.

PORQUEDDU, A. (2013) - Prospezioni archeologiche nell'arcipelago di la Maddalena - Risultati della prima campagna di ricerche. Tese de Specializzazione in Beni Archeologici. Não publicado.

REMOLÀ VALLVERDÚ, J. A. (1998) - Ánforas y modelos de aprovisionamiento en la ciudad tardo-antigua de Tarraco (Diocesis Hispaniarum). In: Saguí (Ed.), Ceramica in Italia: VI-VII secolo. Atti del Colloquio in onore di J.W. Hayes. Biblioteca di Archeologia Medievale 14, p. 797-808

REYNOLDS, Paul (2010) - Hispania and the Roman Mediterranean, AD 100-700 (Ceramics and Trade). London.

RIZZO, G. (2009) - Anfore. In: Lissi Caronna (ed.) Roma (Regio II) - Via di Santo Stefano Rotondo. Scavi nella chiesa di Santo Stefano Rotondo, p. 34282.

ROYAL, Jeffrey G. e TUSA, Sebastiano (2012) - The Levanzo I Wreck, Sicily: a 4th-century AD merchantman in the service of the annona?. The International Journal of Nautical Archaeology 41.1, p. 26-55.

SALVI, Donatella e SANNA, Ignazio (2000) - L'acqua e il tempo. Prospezioni di archeologia subacquea nelle acque di Gonnesa, Comune di Gonnesa e Soprintendenza Archeologica Cagliari e Oristano.

SPANU, P.G. (1997) - Il relitto "A" di Cala Reale (L'Asinara 1). Atti del Convegno nazionale di archeologia subacquea (Anzio 1996), Bari, p. 109-119.

SPANU, P.G. (2006) - Il relitto tardo-antico di Mandriola-A. In: Mastino; Spanu; Zucca (edd.) Tharros Felix 2, Roma, p. 181-196.

STARAC, Alka (2014) - Urban Identity of Pula and roman potery from St. Theodore's Quarter 2005. Actas $28^{\text {th }}$ Congress Rei Cretariae Romanae Fautores, p .175-182.

TCHERNIA, André (2011) - Les Romains et le commerce. Naples - Aix-en-Provence.

UGGERI, Giovanni (2002) - Problemi della rotta Roma-Arles. L'Africa Romana XVI, p. 711-716. 

no Mediterrâneo Ocidental (Séculos III a VI) - Dados preliminares

VALLET, Cecile Batigne ; LEMAÎTRE, Severine e SCHMITT, Anne (2010) - Céramiques Communes et Amphores du début du Ve Siècle à Lyon (Fouilles du Musée Gadagne). In: Menchelli; Santoro; Pasquinucci; Guiducci (Eds), LRCW3 Late Roman Coarse Wares, Cooking Wares and Amphorae in the Mediterranean: Archaeology and archaeometry. Comparison between western and eastern Mediterranean, Volume I, BAR 2185.

VAZ PINTO, I; MAGALHÃES, P. e BRUM, P. (2011) - O Complexo Industrial de Tróia desde os tempos dos Cornelii Bocchi. In: Cardoso; Almagro-Gorbea (Eds.) Lucius Cornelius Bocchus - Escritor Lusitano da Idade de Prata da Literatura Latina, Colóquio Internacional de Tróia 6-8 de Outubro de 2010, Lisboa.

VIEGAS, Catarina (2009) - A ocupação romana do Algarve: estudo do povoamento e economia do Algarve central e oriental no periodo romano. Tese de Doutoramento em Arqueologia, Universidade de Lisboa.

VILAR-SANCHO, B. e MAÑÁ, J. M. (1964) - Informe sobre la excavación arqueológica en la Bahía de San Antonio Abad de Ibiza. Noticiario Arqueológico Hispánico VI, Cuadernos 1-3, p. 177-188.

VILAR-SANCHO, B. e MAÑ́, J. M. 1965 - Informe sobre la segunda fase de la excavación arqueológica realizada en aguas de la Bahía de San Antonio Abad, de Ibiza. Noticiario Arqueológico Hispánico VII, 1-3, p. 188-194.

VILLAVERDE VEGA, Noé (1990) - Comercio marítimo y crisis del s. III en el Círculo del Estrecho. Sus repercusiones en Mauretania Tingitana. Actes du 115eme Congr. Nat. Soc. Sav., Avignón, 1990, Ve Coll. Sur l'bistoire et l'archéologie de l'Afrique du Nord, C.T.H.S., París, p. 333-347

VILLAVERDE VEGA, Noé (2001) - Tingitana en la Antigüedad Tardia (siglos III-VII): Autoctonía y Romanidad en el Extremo Occidente Mediterráneo. R.A.H., Biblioteca Archaeologica Hispana 11, Madrid.

VOLPE, Giuliano (1998) - Archeologia subacquea e commerci in età tardoantica" in Archeologia subacquea. Come opera l'archeologo sott'acqua. Storie dalle acque, Firenze, p. 561-626

VOLPE, Giuliano (2002) - Relitti e rotte commerciali del Mediterraneo occidentale tardoantico. L'Africa Romana XVI, p. 239-250.

WILSON, Andrew (2006) - Fishy Business: Roman Exploitation of Marine Resources. Journal of Roman Archaeology 19.2, p. 525-537.

ZEGGIO, S. e RIZZO, G. (1998) I materiali residui come indicatori della storia di un sito: il caso della fossa di fondazione dell'Arco di Costantino. $M a-$ teriali residui, p. 125-148. 